\title{
Studi Pengolahan Manisan Kering Buah Nipah (Nypa fruticans)
}

\author{
A Study on Processing of Candied Dried Nipah (Nypa fruticans) Fruit
}

\author{
Khusnul Khotimah*, Andi Lisnawati, Muhammad Ardan \\ Program Studi Teknologi Hasil Perkebunan, Politeknik Pertanian Negeri Samarinda, Indonesia. \\ ${ }^{*}$ Corresponding Author: khusnulnew17@gmail.com
}

\begin{abstract}
ABSTRAK
Nipah (Nypa fruticans (thund.)Wurmb)) termasuk tanaman dari suku Palmae dan dikelompokkan ke dalam tanaman hutan mangrove. Nipah merupakan sumber pangan dan energi, namun belum dimanfaatkan secara maksimal sebagai bahan pangan yang memiliki mutu gizi yang tinggi. Dengan komposisi yang tepat, buah nipah bisa dimanfaatkan dan diolah menjadi manisan yang nantinya memiliki nilai ekonomis sebagai sumber penghasilan masyarakat sekitar hutan mangrove. Sebanyak $100 \mathrm{gr}$ buah nipah dipotong kecil. Kemudian direndam air kapur 15 gram kapur/750 ml air selama 15-30 menit lalu dicuci dan ditiriskan. Selanjutnya, buah nipah di-blanching selama 5 menit kemudian dimasak selama 10-15 menit lalu direndam dalam larutan gula $(40 \%, 50 \%$ dan $60 \%$ ) selama 24 jam, kemudian ditiriskan. Untuk mendapatkan manisan kering, digunakan oven dengan suhu $60^{\circ} \mathrm{C}$ selama $10 \mathrm{jam}$. Hasil uji sensoris rasa, warna, aroma dan tekstur yang disukai adalah perlakuan 1 dengan nilai masing-masing adalah 3,49, 3,44, 3,31 dan 3,11. Sedangkan untuk sifat kimia yang masuk dalam SNI Manisan adalah perlakuan 1 dengan kadar air 11\%, kadar abu $0,5 \%$, rendemen $64,33 \%$ dan kandungan gula (total padatan terlarut adalah $12,17 \%$ ).
\end{abstract}

Kata kunci: Buah nipah, perendaman gula, pengeringan buah nipah, manisan kering.

\begin{abstract}
Nipah (Nypa fruticans (thund.)Wurmb)) includes plants from the Palmae tribe and is grouped into mangrove forest plants. Nipah is a source of food and energy, but it has not been maximally utilized as a high-quality nutritious food. With the right composition, nipah fruit can be used and processed into sweets which later will have economic value as a source of income for the community around the mangrove forest. A total of $100 \mathrm{gr}$ of Nipah fruit was cut into small pieces. Nipah fruit was then soaked in chalk water (15 grams of chalk / $750 \mathrm{ml}$ of water) for 15-30 minutes then washed and drained well. The fruit was then blanched for 5 minutes and cooked for 10-15 minutes and then soaked in a sugar solution (40\%, 50\% and $60 \%)$ for 24 hours, then drained. To get dried sweets, an oven dryer was used with a temperature of $60^{\circ} \mathrm{C}$ for 10 hours. The results of sensory test sowed that the $1^{\text {st }}$ treatment (40\% sugar solution) was preferred for taste, color, aroma and texture with the values of 3.49, 3.44, 3.31 and 3.11, respectively. In addition, the chemical properties of candied dried nipah fruit produced by treatment 1 (40\% sugar solution) meet the criteria of Indonesian Standard (SNI) for sweets with a moisture of $11 \%$, ash content of $0.5 \%$, rendement of $64.33 \%$ and sugar content (total dissolved solids of $12.17 \%$ ).
\end{abstract}

Keywords: nipah fruit, soaking sugar, nipah fruit drying, dried candied sweet.

\section{PENDAHULUAN}

Nipah (Nypa fruticans (thund.)Wurmb)) termasuk tanaman dari suku Palmae, tumbuh di sempanjang sungai yang terpengaruh pasang surut air laut. Tumbuhan ini dikelompokkan pula ke dalam tanaman hutan mangrove. Tanaman tumbuh rapat bersama, seringkali membentuk komunitas murni yang luas di sempanjang sungai dekat muara hingga sungai dengan air payau (Kitamura et al.,1997).

Nipah merupakan sumber pangan dan energi, namun belum banyak dipublikasi mengenaipotensi maupun pemanfaatannya. Padahal hampir disebagian besar sungai yang masih terpengaruh oleh pasangnya air laut banyak dijumpai tumbuhan nipah dengan populasi yang sangat besar. Oleh karena itu perlu penanganan terhadap tanaman nipah khususnya pemanfaatan buah nipah sebagai produk makanan. Pembuatan manisan nipah kering merupakan salah satu upaya pemanfaatan buah nipah yang dapat meningkatkan potensi dan juga dapat menjadi alternative usaha.

Perlu dilakukan penelitian mengenai proses pengolahan buah nipah menjadi manisan kering untuk mengoptimalkan pemanfaatan buah nipah dengan konsentrasi gula yang berbeda, sehingga 
buah nipah mempunyai nilai ekonomis bagi masyarakat disekitar hutan Nipah, sehingga dapat dijadikan usaha bagi masyarakat.

Manisan adalah meningkatkan kadar gula dalam buah sehingga tidak sesuai lagi bagi pertumbuhan mikroorganisme yang merugikan. Manisan merupakan salah satu jenis makanan ringan yang biasanya menggunakan gula pasir sebagai bahan pemanisnya. Pemberian gula dalam konsentrasi tinggi bertujuan selain memberikan rasa manis juga berguna untuk mencegah pertumbuhan mikroba (Departemen perindustrian : 1983).

Manisan merupakan salah satu bentuk pangan olahan yang banyak disukai masyarakat. Rasanya yang manis bercampur rasa khas buah cocok untuk dinikmati dalam berbagai kesempatan. Manisan merupakan salah satu produk yang mengandung kadar gula tinggi. Dengan kadar gula tinggi ini, produk manisan dapat disimpan dalam jangka waktu yang relative lama. Pembuatan manisan juga merupakan salah satu alternative memperpanjang daya simpan bahan pangan (Fachruddin, 2006).

Manisan biasanya dibuat dari buah. Produk ini merupakan bahan setengah kering dengan kadar air sekitar $30 \%$, dan kadar gula tinggi $(>60 \%)$. Kondisi ini memungkinkan manisan dapat disimpan lama karena kebanyakan mikroba tidak dapat tumbuh pada bahan. Produk ini merupakan alternative usaha yang mungkin menguntungkan karena cara pembuatannya sederhana, biaya tidak mahal, dan penampilan produk cukup menarik (Hertami, 1976).

Manisan buah pada umumnya dibedakan atas manisan buah basah, manisan semi basah dan manisan kering. Manisan basah sering dikonsumsi bersama sirup gula atau dilumuri gula pekat bekas perendamannya. Sementara itu, manisan semi basah merupakan manisan yang proses pembuatannya direndam dengan larutan gula pekat dan melalui pengeringan tetapi hasilnya tidak benar-benar kering, memiliki kadar air moderat $>50 \%$, memiliki aktivitas air (aw) sebesar 0,6-0,9, dan mempunyai tekstur yang elastis. Sedangkan pada manisan kering merupakan manisan buah yang dikeringkan dibawah sinar matahari atau menggunakan oven pengeringan setelah direndam dalam air gula pekat. Pada dasarnya, pembuatan manisan buah tidak memerlukan proses rumit. Teknologi yang digunakan dapat dipilih yang sederhana dan mudah diterapkan oleh pemula di tingkat industri rumah tangga (Saptoningsih dan jatnika, 54:2002).

\section{METODE PENELITIAN}

\section{A. Alat Dan Bahan}

Bahan yang digunakan adalah: Buah nipah, gula, air, kapur serta aquades.

Alat yang digunakanantara lain: pisau, baskom, timbangan, kompor, panci, toples, talenan, oven, dan sendok, cawan petri, botol timbang, oven, timbangan analitik, spatula, desikator tanur, penjepit, desikator, refraktometer, mortar, pipet, dan gelas ukur.

\section{B. Pelaksanaan Penelitian Rancangan Penelitian dan Analisis Data}

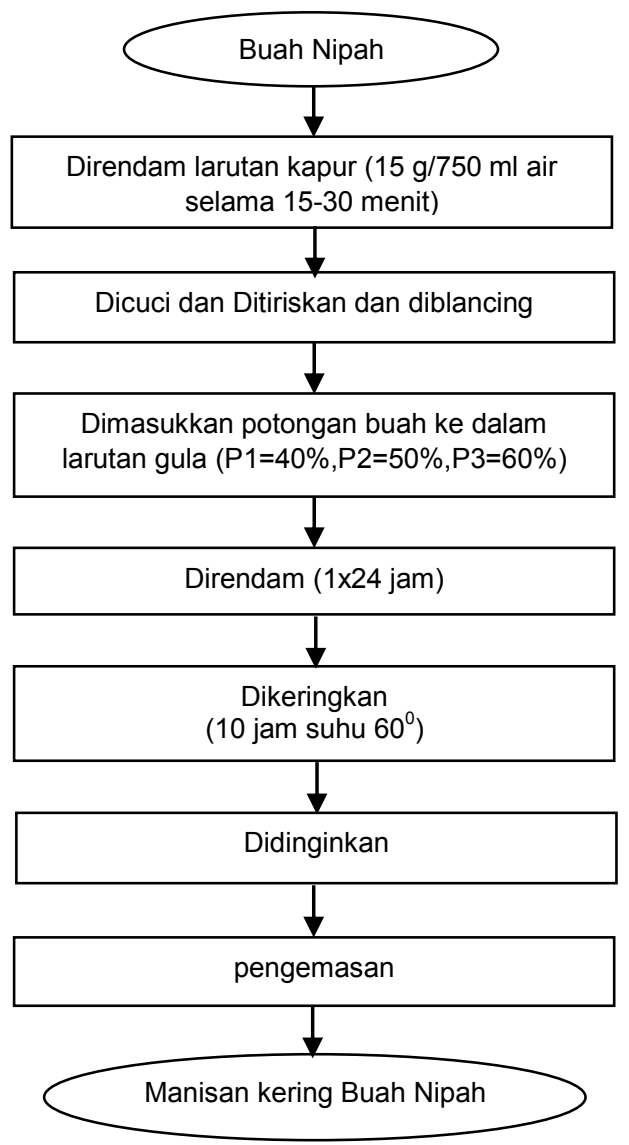

Gambar 1. Diagram Alir Pengolahan Manisan Kering Buah Nipah 
Penelitian ini menggunakan RAL satu faktor perlakuan dengan $3 x$ ulangan. Faktor tersebut adalah konsetrasi gula yang berbeda $(40 \%, 50 \%, 60 \%)$. Sebanyak 100 gr buah nipah dipotong kecil.Kemudian konsentrasi $40 \%$, 50\% dan $60 \%$ dan dimasak selama 10-15 menit dan direndam dalam larutan gula selama 24 jam, lalu ditiriskan. Untuk mendapatkan manisan kering digunakan oven dengan suhu $60^{\circ} \mathrm{C}$ selama 10 jam.

\section{Pengujian}

1. Uji Kadar Air Metode SNI-01-28911992 (Dewan Standarisasi Nasional, 1992)

Ditimbang sampel $2 \mathrm{~g}$ diletakkan pada botol timbang bertutup yang telah diketahui bobotnya.Selanjutnya sampel dikeringkan pada oven dengan suhu $105^{\circ} \mathrm{C}$ selama 3 jam. Kemudian sampel didinginkan dalam desikator dan ditimbang, dan ulangin pekerjaan ini hingga diperoleh botot tetap.

$$
\text { Kadar air }=\frac{\mathrm{W}}{\mathrm{W} 1} \quad 100 \%
$$

Keterangan:

W : bobot cuplikan sebelum dikeringkan (g)

W1 : kehilangan bobot setelah dikeringkan (g)

\section{Rendemen}

Berat akhir produk direndam air kapur 15 gram kapur/750 ml air selama 15-30 menit lalu dicuci dan ditiriskan. Buah nipah lalu diblancing selama 5 menit dan disiapkan larutan gula dengan

$$
\text { Rendemen }=\frac{\begin{array}{c}
\text { Berat akhir } \\
\text { produk }
\end{array}}{\begin{array}{l}
\text { B.Awal } \\
\text { produk }
\end{array}} \times 100 \%
$$

\section{Analisis Kadar Gula (Derajat Brix)}

Analisa ini digunakan untuk mengetahui kadar gula pada sirup sesuai SNI. Pengukuran ini dilakukan dengan cara meneteskan produk (sirup) pada kaca sensor yang ada pada refraktometer dan angka Brix akan segera terbaca (Norman, 1998 dalam Butar-butar, 2011)

\section{Uji Sensoris}

Kriteria penilaian meliputi:rasa, warna, aroma dan tekstur

\section{HASIL DAN PEMBAHASAN}

\section{A. Uji Sensoris Warna Manisan Buah Nipah}

Uji sensoris warna dilakukan oleh 15 panelis, bila nilai tingkat kesukaan tinggi maka manisan buah nipah disukai konsumen dan sebaliknya jika tingkat kesukaan rendah maka tingkat kesukaan warna rendah. Hasil dapat dilihat pada Tabel 1.

Tabel 1. Nilai Rata-rata Warna Manisan buah nipah

\begin{tabular}{cccccc}
\hline \multirow{2}{*}{ Perlakuan } & \multicolumn{3}{c}{ Ulangan } & Jumlah & Rata-rata \\
\cline { 2 - 4 } & $\mathbf{1}$ & $\mathbf{2}$ & $\mathbf{3}$ & & 3,44 \\
\hline P1 & 3,33 & 3,6 & 3,4 & 10,33 & 3,62 \\
P2 & 3,60 & 3,53 & 3,73 & 10,86 & 3,60 \\
P3 & 3,40 & 3,80 & 3,60 & 10,80 & 3,55 \\
\hline Jumlah & 10,33 & 10,93 & 10,73 & 31,99 & \\
\hline
\end{tabular}

Sumber: Data primer setelah diolah (2018)

Keterangan: $\mathrm{P} 1=40 \%$ gula $\mathrm{P} 2=50 \%$ dan $\mathrm{P} 3=60 \%$

Perlakuan P2 memiliki rata-rata nilai lebih tinggi dari perlakuan P1 dan P3 yaitu 3,62 (suka) dengan kriteria warna putih cerah, kemudian P3 dengan rata-rata 3,60 (suka) dengan kriteria putih pucat dan terakhir adalah $\mathrm{P} 1$ dengan rata-rata 3,44 (suka) dengan kriteria kuning pucat. Secara keseluruhan ketiga perlakuan masih masuk dalam range penilaian disukai.

Warna merupakan faktor yang dapat digunakan sebagai indikator kesegaran atau kematangan suatu produk. Warna merupakan daya tarik terbesar untuk menikmati aroma makanan. Warna dalam makanan dapat meningkatkan penerimaan 
konsumen tentang sebuah produk. Konsumen cenderung lebih menyukai bahan pangan dengan warna yang cerah.

Warna merupakan daya tarik terbesar untuk menikmati makanan setelah aroma. Pewarna dalam pangan dapat meningkatkan penerimaan konsumen terhadap suatu produk (Dixit et al, 1995).

Warna adalah salah satu daya tarik utama saat konsumen pertama kali melihat suatu produk. Bersama-sama dengan aroma, tekstur dan rasa, warna berperan dalam tingkat penerimaan suatu makanan. Secara visual faktor warna tampil lebih dahulu dari bahan yang bergizi, enak, dan teksturnya sangat baik. Dan bahan pangan jika warnanya telah menyimpang maka tidak akan dikonsumsi oleh konsumen
Handajani (2010) dalam Renate dan Nurlismita (2015). Warna makanan memegang peranan utama dalam penampilan makanan, karena meskipun makanan tersebut lezat, tetapi penampilannya tidak menarik waktu disajikan, akan mengakibatkan selera orang yang akan memakannya menjadi hilang (Moehyi,1992). Hal ini didukung oleh Sanjur (1982) bahwa penampakan dari makanan dan minuman merupakan hal yang paling banyak mempengaruhi preferensi dan kesukaan konsumen.

Hasil uji organoleptik kemudian dianalisa menggunakan analisa sidik ragam. Analisa sidik ragam warna manisan buah nipah dengan konsentrasi gula yang berbeda dapat dilihat dalam Tabel 2 .

Tabel 2. Analisa Sidik Ragam Warna Manisan Buah Nipah

\begin{tabular}{ccccccc}
\hline $\begin{array}{c}\text { Sumber } \\
\text { Keragaman }\end{array}$ & $\begin{array}{c}\text { Derajat } \\
\text { Bebas }\end{array}$ & $\begin{array}{c}\text { Jumlah } \\
\text { Kuadrat }\end{array}$ & $\begin{array}{c}\text { Kuadrat } \\
\text { Tengah }\end{array}$ & FHitung & \multicolumn{2}{c}{ Ftabel } \\
\cline { 6 - 7 } Perlakuan & 2 & 0,06 & 0,03 & $1,20^{\text {tn }}$ & 5,14 & 10,92 \\
Galat & 6 & 0,14 & 0,02 & & & \\
\hline Total & 8 & 0,20 & & & & \\
\hline
\end{tabular}

Keterangan: $\left({ }^{\mathrm{tn}}\right)$ tidak berbeda nyata

Hasil analisa sidik ragam menunjukkan bahwa warna manisan buah nipah dengan pengaruh konsentrasi gula yang berbeda yang dihasilkan tidak berbeda nyata.

\section{B. Uji Sensoris Aroma}

Pada Tabel 3, menunjukkan rata-rata nilai kesukaan terhadap aroma yang paling tinggi adalah P1 yaitu 3,31 (suka) dan P3 dengan nilai 3,31 (agak suka). Sedangkan yang terendah adalah pada perlakuan P2 dengan konsentrasi gula $50 \%$ dengan nilai rata-rata 3,24 (suka).

Uji sensoris manisan buah nipah dilakukan oleh 15 panelis. Bila nilai tingkat kesukaan terhadap rasa rendah, maka manisan buah nipah kurang disukai oleh konsumen, tetapi jika nilai tingkat kesukaan tinggi maka disukai oleh konsumen. Hasil uji sensoris rasa dapat dilihat pada Tabel 3.

Tabel 3. Nilai Rata-rata Aroma Manisan Buah Nipah

\begin{tabular}{cccccc}
\hline \multirow{2}{*}{ Perlakuan } & \multicolumn{3}{c}{ Ulangan } & \multirow{2}{*}{ Jumlah } & Rata-rata \\
\cline { 2 - 4 } & $\mathbf{1}$ & $\mathbf{2}$ & $\mathbf{3}$ & & 3,31 \\
\hline P1 & 3,20 & 3,20 & 3,53 & 9,93 & 3,24 \\
P2 & 3,33 & 3,20 & 3,20 & 9,73 & 3,31 \\
\hline P3 & 3,20 & 3,47 & 3,27 & 9,94 & 3,29 \\
\hline Jumlah & 9,73 & 9,87 & 10 & 29,6 &
\end{tabular}

Sumber : Data primer setelah diolah (2018)

Keterangan : $\mathrm{P} 1=40 \%$ gula $\mathrm{P} 2=50 \%$ dan $\mathrm{P} 3=60 \%$ 
Hasil analisa sidik ragam pada aroma manisan buah nipah dengan pengaruh konsentrasi gula yang berbeda diperoleh hasil yang tidak berbeda nyata. Hal ini menunjukkan bahwa tingkat kesukaan dari 15 panelis terhadap aroma manisan buah nipah dengan konsentrasi gula yang berbeda menunjukan sama. Analisa Sidik ragam aroma dapat dilihat pada Tabel 4.

Tabel 4. Analisa Sidik Ragam Aroma Manisan Kering Buah Nipah

\begin{tabular}{ccccccc}
\hline \multirow{2}{*}{$\begin{array}{c}\text { Sumber } \\
\text { Keragaman }\end{array}$} & $\begin{array}{c}\text { Derajat } \\
\text { Bebas }\end{array}$ & $\begin{array}{c}\text { Jumlah } \\
\text { Kuadrat }\end{array}$ & $\begin{array}{c}\text { Kuadrat } \\
\text { Tengah }\end{array}$ & FHitung & \multicolumn{2}{c}{ Ftabel } \\
\cline { 6 - 7 } Perlakuan & 2 & 0,01 & 0,005 & $1,20^{\text {tn }}$ & 5,14 & 10,92 \\
Galat & 6 & 0,13 & 0,021 & & & \\
\hline Total & 8 & 0,20 & & & & \\
\hline
\end{tabular}

Keterangan: $\left({ }^{\mathrm{tn}}\right)$ tidak berbeda nyata

Hasil analisa sidik ragam pada aroma manisan buah nipah dengan pengaruh konsentrasi gula yang berbeda diperoleh hasil yang tidak berbeda nyata. Dari hasil tersebut menunjukkan bahwa tingkat kesukaan dari 15 panelis terhadap rasa manisan buah nipah dengan konsentrasi gula yang berbeda menunjukan sama.

\section{Uji Sensoris Tekstur}

Pengujian tekstur pada manisan buah nipah sangat penting dilakukan, karena tekstur merupakan hal yang harus disesuaikan dengan jenis suatu produk. Panelis akan suka jika tekstur tidak terlalu keras dan terlalu lembek. Hasil lengkap uji organoleptik tekstur dapat dilihat pada Tabel 5.

Tabel 5. Nilai Rata-Rata Tekstur Manisan Buah Nipah

\begin{tabular}{cccccc}
\hline \multirow{2}{*}{ Perlakuan } & \multicolumn{3}{c}{ Ulangan } & \multirow{2}{*}{ Jumlah } & Rata-rata \\
\cline { 2 - 4 } & $\mathbf{1}$ & $\mathbf{2}$ & $\mathbf{3}$ & & 3,11 \\
\hline P1 & 3,07 & 2,8 & 3,47 & 9,34 & 2,87 \\
P2 & 2,93 & 2,8 & 2,87 & 8,6 & 2,84 \\
P3 & 2,53 & 3,33 & 2,67 & 8,53 & 2,94 \\
\hline Jumlah & 8,53 & 8,93 & 9,01 & 26,47 & \\
\hline
\end{tabular}

Sumber : Data primer setelah diolah (2018)

Keterangan: $\mathrm{P} 1=40 \%$ gula $\mathrm{P} 2=50 \%$ dan $\mathrm{P} 3=60 \%$

Tekstur merupakan suatu hal yang berhubungan dengan struktur makanan yang dirasakan di mulut.

Tekstur juga bisa diartikan sebagai penginderaan yang dihubungkan dengan rabaan atau sentuhan. Kadang-kadang tekstur juga dianggap sama penting dengan bau, rasa dan aroma karena mempengaruhi citarasa makanan.Tekstur meliputi rasa garing, keempukan dan kekerasan makanan yang dirasakan oleh indera pengecap. Tekstur dapat mempengaruhi rasa yang ditimbulkan oleh makanan. Tekstur makanan selain ditentukan oleh mutu bahan makanan yang digunakan juga ditentukan oleh cara mengolah/memasak.Tekstur makanan juga adalah salah satu komponen yang ikut menentukan citarasa makanan karena sensitivitas indera cita rasa dipengaruhi oleh konsistensi makanan (Renate dan Nurlismita, 2015). Makanan yang berkonsistensi padat/kental akan memberikan rangsang yang lebih lambat terhadap indera kita. Tekstur pada manisan buah nipah dipengaruhi oleh konsentrasi gula.

Hasil perhitungan uji sensoris tekstur manisan buah nipah, dapat terlihat nilai dari ketiga perlakuan. $\mathrm{P} 1(3,11)$ berada dalam range penilaian suka memiliki rata-rata nilai lebih tinggi dari perlakuan P2 $(2,87)$ berada dalam range penilaian agak suka dan $\mathrm{P} 2$ lebih tinggi dari P3 $(2,84)$ berada dalam 
range penilaian agak suka. Konsentrasi gula yang tinggi dapat menurunkan kadar air sehingga tekstur dari manisan kering buah nipah menjadi keras. Dimana konsumen tidak menyukai tekstur makanan yang terlalu keras. Menurut Purnomo (1995), gula bersifat higroskopis menyebabkan terikatnya sebagian kandungan air dalam bahan sehingga air bebas menjadi berkurang. Semakin tinggi jumlah gula yang ditambahkan maka semakin tinggi jumlah air bebas yang terikat, sehingga kadar air dalam bahan menjadi rendah. Kadar air manisan pepaya kering yang dihasilkan masih dalam standar yang diinginkan yaitu dibawah $20 \%$. Winarno (1993) menyatakan kadar air merupakan banyaknya air yang terkandung dalam bahan yang dinyatakan dalam persen. Kadar air juga salah satu karakteristik yang sangat penting pada bahan pangan, karena air dapat mempengaruhi tekstur.

Tabel 6. Analisa Sidik Ragam Tekstur Manisan Buah Nipah

\begin{tabular}{ccccccc}
\hline $\begin{array}{c}\text { Sumber } \\
\text { Keragaman }\end{array}$ & $\begin{array}{c}\text { Derajat } \\
\text { Bebas }\end{array}$ & $\begin{array}{c}\text { Jumlah } \\
\text { Kuadrat }\end{array}$ & $\begin{array}{c}\text { Kuadrat } \\
\text { Tengah }\end{array}$ & Fhitung & \multicolumn{2}{c}{ Ftabel } \\
\cline { 6 - 7 } Perlakuan & 2 & 0,13 & 0,07 & 0,67 & $5,14^{\text {tn }}$ & 10,92 \\
Galat & 6 & 0,60 & 0,10 & & & \\
\hline Total & 8 & 10,13 & & & & \\
\hline
\end{tabular}

Keterangan: $\left({ }^{\mathrm{tn}}\right)$ Tidak berbeda nyata

Hasil sidik ragam memperlihatkan bahwa manisan buah nipah konsentrasi gula yang berbedatidak berbeda nyata. Walaupun konsentrasi gula pada setiap perlakuan berbeda, proses pembuatan setiap perlakuan adalah sama, sehingga tekstur manisan buah nipah dengan pengaruh konsentrasi gula yang berbedayang diperoleh tidak berbeda nyata. Dari hasil tersebut juga menggambarkan bahwa tingkat kesukaan panelis terhadap tekstur manisan buah nipah dengan pengaruh konsentrasi gula yang berbeda tidak berbeda nyata (sama).

\section{Uji Sensoris Rasa}

Data hasil uji sensoris rasa manisan buah nipah dapat dilihat pada Tabel 7 di bawah ini :

Tabel 7. Nilai Rata-Rata Uji Rasa Manisan Buah Nipah

\begin{tabular}{cccccc}
\hline \multirow{2}{*}{ Perlakuan } & \multicolumn{3}{c}{ Ulangan } & \multirow{2}{*}{ Jumlah } & Rata-rata \\
\cline { 2 - 4 } & $\mathbf{1}$ & $\mathbf{2}$ & $\mathbf{3}$ & & 3,49 \\
\hline P1 & 3,67 & 3,07 & 3,73 & 10,47 & 3,42 \\
P2 & 3,33 & 3,33 & 3,6 & 10,26 & 3,29 \\
P3 & 3,2 & 3,33 & 3,33 & 9,86 & 3,40 \\
\hline Jumlah & 10,2 & 9,73 & 10,66 & 30,59 & \\
\hline
\end{tabular}

Sumber : Data primer setelah diolah (2018)

Keterangan: $\mathrm{P} 1=40 \%$ gula $\mathrm{P} 2=50 \%$ dan $\mathrm{P} 3=60 \%$

Dari hasil perhitungan uji organoleptik rasa manisan kering buah nipah, dapat diketahui bahwa P3 memiliki rata-rata nilai lebih rendah dari perlakuan P1 dan P2. Dapat dilihat pada tabel diatas adalah P1 (konsentrasi gula 50\%) dengan rata-rata 3,49 (suka), kemudian disusul P2 (konsentrasi $50 \%$ ) dengan rata-rata 3,42 (suka), sedangkan yang paling rendah adalah P3 dengan rata-rata 3,29 dan (suka). Secara keseluruhan terlihat perlakuan P1, P2 dan P3 masuk dalam kategori 'disukai'. Hal ini karena konsentrasi gula dengan perbedaan $10 \%$ tidak mempengaruhi rasa dari manisan buah nipah. 
Tabel 8. Analisa Sidik Ragam Rasa Manisan Buah Nipah

\begin{tabular}{ccccccc}
\hline $\begin{array}{c}\text { Sumber } \\
\text { Keragaman }\end{array}$ & $\begin{array}{c}\text { Derajat } \\
\text { Bebas }\end{array}$ & $\begin{array}{c}\text { Jumlah } \\
\text { Kuadrat }\end{array}$ & $\begin{array}{c}\text { Kuadrat } \\
\text { Tengah }\end{array}$ & Fhitung & \multicolumn{2}{c}{ Ftabel } \\
\hline Perlakuan & 2 & 0,06 & 0,03 & 0,58 & 5,14 & 10,92 \\
Galat & 6 & 0,33 & 0,05 & & & $\mathbf{1 \%}$ \\
\hline Total & 8 & 0,39 & & &
\end{tabular}

Keterangan: $\left({ }^{\mathrm{tn}}\right)$ Tidak berbeda nyata

Hasil dari analisa sidik ragam terhadap rasa manisan buah nipah didapatkan hasil yang tidak berbeda nyata karena pada tingkat tersebut masih dalam kisaran aroma normal manisan buah nipahdan belum terlalu menyimpang serta belum menunjukkan perubahan aroma yang sebenarnya. Dari hasil tersebut dapat disimpulkan bahwa tingkat kesukaan dari 15 panelis terhadap rasa manisan buah nipah dengan pengaruh konsentrasi gula yang berbeda sama atau tidak berbeda nyata.

\section{E. Kadar Air Manisan Buah Nipah}

Air merupakan salah satu unsur penting dalam bahan pangan, meskipun bukan sumber nutrient namun keberadaannya sangat esensial dalam kelangsungan proses biokimiawi organisme hidup. Kadar air merupakan banyaknya air yang terkandung dalam bahan yang dinyatakan dalam persen. Air merupakan komponen penting yang mempengaruhi penampakkan, tekstur dan cita rasa makanan (Winarno, 1995).

Uji kadar air dilakukan pada sembilan sampel manisan kering buah nipah dengan perbedaan konsentrasi gula yaitu $40 \%$ untuk perlakuan satu, $50 \%$ untuk perlakuan dua dan $60 \%$ untuk perlakuan tiga.

Tabel 9. Kadar Air Manisan Buah Nipah

\begin{tabular}{cccccc}
\hline \multirow{2}{*}{ Perlakuan } & \multicolumn{3}{c}{ Ulangan } & Jumlah & Rata-rata \\
\cline { 2 - 4 } & $\mathbf{1}$ & $\mathbf{2}$ & $\mathbf{3}$ & & 19,40 \\
\hline P1 & 15,82 & 24,18 & 18,19 & 58,19 & 16,12 \\
P2 & 21,02 & 8,27 & 19,07 & 48,37 & 11,71 \\
P3 & 8,68 & 17,30 & 9,16 & 35,14 & 15,75 \\
\hline Jumlah & & & 141,71 & \\
\hline
\end{tabular}

Sumber : Data primer setelah diolah (2018)

Keterangan: $\mathrm{P} 1=40 \%$ gula $\mathrm{P} 2=50 \%$ dan $\mathrm{P} 3=60 \%$

Hasil uji kadar air pada manisan buah nipah dengan konsentrasi gula yang berbeda menunjukkan bahwa P1 memiliki kadar air tertinggi yaitu $19.40 \%$ dimana P1 adalah pembuatan manisan buah nipah dengan konsentrasi gula 40\%. P2 memiliki kadar gula yang lebih tinggi dari P3 tetapi lebih rendah dari P1 yaitu $16.12 \%$ dimana P2 adalah pembuatan manisan buah nipah dengan konsentrasi gula 50\%. P3 memiliki kandungan air terendah bila dibandingkan dengan P1 dan P2 yaitu $11.71 \%$ dimana P3 adalah pembuatan manisan buah nipah dengan konsentrasi gula 60\%. Tingginya kandungan air pada konsentrasi gula yang terendah disebabkan oleh proses osmosis.

Menurut Apriyantono dkk (1989), ada kecenderungan bahwa semakin tinggi konsentrasi gula yang dicobakan maka kandungan air semakin menurun hal ini disebabkan buah nipah yang direndam dalam larutan gula akan mengalami tekanan osmosis yaitu tekanan molekulmolekul gula pada dinding sel (extra sel) buah sampai larutan gula masuk ke dalamnya, akibatnya air yang berada dalam 
sel buah keluar. Perbedaan aliran air keluar dan aliran gula masuk akan menyebabkan struktur sel dan tekstur buah menjadi keras, karena semakin tinggi aliran gula masuk maka tekanan osmosis semakin kuat dan akibatnya air akan semakin banyak yang keluar dari bahan. Selain itu menurut Desrosier (1988) menyatakan bahwa gula mempunyai daya larut yang tinggi, kemampuan mengurangi kelembaban relatif dan mengikat air sehingga menyebabkan kadar air dalam bahan pangan menjadi berkurang. Air yang terdapat dalam bentuk bebas dapat membantu terjadinya proses kerusakan bahan makanan misalnya proses mikrobiologis, kimiawi, enzimatik, bahkan oleh aktivitas serangga perusak (Sudarmadji, 2003).

Analisa sidik ragam kadar air dari manisa buah Nipah dapat dilihat pada Tabel 10.

Tabel 10. Analisa Sidik Ragam Kadar Air Manisan Buah Nipah

\begin{tabular}{ccccccc}
\hline $\begin{array}{c}\text { Sumber } \\
\text { Keragaman }\end{array}$ & $\begin{array}{c}\text { Derajat } \\
\text { Bebas }\end{array}$ & $\begin{array}{c}\text { Jumlah } \\
\text { Kuadrat }\end{array}$ & $\begin{array}{c}\text { Kuadrat } \\
\text { Tengah }\end{array}$ & Fhitung & \multicolumn{2}{c}{ Ftabel } \\
\hline Perlakuan & 2 & 89,19 & 44,59 & 1,50 & $5,14^{\text {tn }}$ & 10,92 \\
Galat & 6 & 178,40 & 29,73 & & & \\
\hline Total & 8 & 0,39 & & & & \\
\hline Keterangan: $\left(^{\text {tn }}\right)$ Tidak berbeda nyata & & & &
\end{tabular}

Keterangan: $\left({ }^{\mathrm{tn}}\right)$ Tidak berbeda nyata

Hasil analisa sidik ragam menunjukkan bahwa kadar air manisan kering nipah dengan konsentrasi gula yang berbeda yang dihasilkan tidak berbeda nyata tetapi kadar airnya cenderung menurun, dengan kadar air pada perlakuan P1 dengan nilai tertinggi $(19,40)$, dan P3 dengan nilai kadar air terendah $(11,71)$ pada manisan kering buah nipah. Hal ini disebabkan karena perlakuan (konsentrasi gula) yang diberikan tidak memiliki jarak yang jauh yaitu hanya $10 \%$ antara perlakuan. Dari hasil yang diperoleh menunjukkan bahwa tingkat kandungan kadar air dari 9 sampel manisan kering buah nipah dengan konsentrasi gula yang berbeda, hasilnya sama atau tidak berbeda nyata.

\section{F. Kadar Abu Manisan Buah Nipah}

Pengukuran kadar abu bertujuan untuk mengetahui besarnya kandungan mineral yang terdapat pada manisan buah Nipah. Uji kadar abu dilakukan pada sembilan sampel manisan kering buah nipah dengan perbedaan konsentrasi gula yaitu $40 \%$ untuk perlakuan satu, $50 \%$ untuk perlakuan dua dan $60 \%$ untuk perlakuan tiga. Setiap perlakuan diulang sebanyak 3 kali.

Tabel 11. Kadar Abu Manisan Buah Nipah

\begin{tabular}{cccccc}
\hline \multirow{2}{*}{ Perlakuan } & \multicolumn{3}{c}{ Ulangan } & Jumlah & Rata-rata \\
\cline { 2 - 4 } & $\mathbf{1}$ & $\mathbf{2}$ & $\mathbf{3}$ & & \\
\hline P1 & 0,56 & 0,34 & 0,58 & 1,49 & 0,50 \\
P2 & 0,19 & 0,22 & 0,20 & 0,61 & 0,20 \\
P3 & 0,25 & 0,35 & 0,40 & 1,01 & 0,34 \\
\hline Jumlah & & & & 3,11 & 0,35 \\
\hline
\end{tabular}

Sumber : Data primer setelah diolah (2018),

Keterangan: $\mathrm{P} 1=40 \%$ gula $\mathrm{P} 2=50 \%$ dan $\mathrm{P} 3=60 \%$ 


\begin{abstract}
Hasil uji kadar abu pada pembuatan manisan nipah dengan pengaruh konsentrasi yang berbeda. Nilai kadar abu yang teritinggi terdapat pada perlakuan 1 yaitu 0.50 dimana perlakuan 1 adalah pembuatan manisan buah nipah dengan konsentrasi gula $40 \%$. Nilai kadar abu yang terendah terdapat pada perlakuan 2 yaitu 0.20 dimana perlakuan 2 adalah pembuatan manisan buah nipah dengan konsentrasi gula $50 \%$. Sedangkan pada perlakuan 3 yaitu 0.34 dimana perlakuan 3 adalah pembuatan manisan buah nipah dengan konsentrasi gula $60 \%$. Seharusnya data kadar abu meningkat seiring dengan meningkatnya konsentrasi gula. Dimana gula memiliki kadar abu, $92 \mathrm{mg} / 100 \mathrm{~g}$. Perbedaan nyata dari berbagai perlakuan
\end{abstract}

lebih disebabkan oleh kandungan abu dari gula pasir dimana terkandung abu 92 $\mathrm{mg} / 100 \mathrm{~g}$ bahan (Brautlecht 1953). Hasil analisa kadar abu yang didapatkan mengalami penurunan dari P1 (40\%), P2 $(50 \%)$ dan P3 $(60 \%)$. Hal ini diduga karena tingkat kematangan yang berbeda menghasilkan kadar abu yang berbeda. Menurut Harefa dan Pato (2017) bahwa semakin tinggi tingkat kematangan buah maka akan semakin meningkatkan kadar abu pada buah tersebut yang disebabkan semakin tingginya kandungan garamgaram mineral yang terkandung dalam buah yang terbentuk seiring proses pematangan atau pemasakan buah nipah.

Tabel 12. Analisa Sidik Ragam Kadar Abu Manisan Buah Nipah

\begin{tabular}{ccccccc}
\hline $\begin{array}{c}\text { Sumber } \\
\text { Keragaman }\end{array}$ & $\begin{array}{c}\text { Derajat } \\
\text { Bebas }\end{array}$ & $\begin{array}{c}\text { Jumlah } \\
\text { Kuadrat }\end{array}$ & $\begin{array}{c}\text { Kuadrat } \\
\text { Tengah }\end{array}$ & Fhitung & \multicolumn{2}{c}{ Ftabel } \\
\hline Perlakuan & 2 & 0,13 & 0,06 & 7,98 & $5,14^{\text {tn }}$ & 10,92 \\
Galat & 6 & 0,17 & 0,01 & & & \\
\hline Total & 8 & 0,30 & & & & \\
\hline
\end{tabular}

Keterangan: ( ) berbeda nyata

Hasil analisa sidik ragam menunjukkan bahwa kadar abu manisan kering buah nipah dengan konsentrasi gula yang berbeda yang dihasilkan berbeda nyata. Hal ini disebabkan oleh perlakuan konsentrasi gula karena gula memilliki kadar abu 92mg/100 g, semakin tinggi konsentrasi gula cenderung meningkatkan kadar abu pada manisan kering buah nipah, namun pada penelitian ini perbedaan kadar abu yang berbeda nyata juga disebabkan oleh tingkat kematangan buah nipah yang digunakan.

\section{G. Rendemen Manisan Buah Nipah}

Pengujian rendemen dilakukan dengan berat manisan yang didapatkan dibagi dengan berat bahan awal. Uji kadar perhitungan rendemen dilakukan pada sembilan sampel manisan kering buah nipah dengan perbedaan konsentrasi gula yaitu $40 \%$ untuk perlakuan satu, $50 \%$ untuk perlakuan dua dan $60 \%$ untuk perlakuan tiga. Setiap perlakuan diulang sebanyak 3 kali.

Tabel 13. Rendemen Manisan Buah Nipah

\begin{tabular}{|c|c|c|c|c|c|}
\hline \multirow{2}{*}{ Perlakuan } & \multicolumn{3}{|c|}{ Ulangan } & \multirow{2}{*}{ Jumlah } & \multirow{2}{*}{ Rata-rata } \\
\hline & 1 & 2 & 3 & & \\
\hline P1 & 64,00 & 64,00 & 65,00 & 193,00 & 64,33 \\
\hline P2 & 65,00 & 63,00 & 65,00 & 193,00 & 64,33 \\
\hline P3 & 63,00 & 60,00 & 69,00 & 192,00 & 64,00 \\
\hline & & & & 578,00 & 192,67 \\
\hline
\end{tabular}

Sumber : Data primer setelah diolah (2018),

Keterangan: $\mathrm{P} 1=40 \%$ gula $\mathrm{P} 2=50 \%$ dan $\mathrm{P} 3=60 \%$ 
Hasil perhitungan rendemen manisan buah nipah dengan pengaruh perbedaan konsentrasi gula. Pada P1 dengan konsentrasi gula $40 \%$ rendemen yang didapatkan adalah 64.33\%. Pada P2 dengan konsentrasi gula $50 \%$ rendemen yang didapatkan adalah $64.33 \%$. Pada P3 dengan konsentrasi gula $60 \%$ rendemen yang didapatkan adalah $64 \%$. Dari ketiga perlakuan tersebut dapat dilihat bahwa penyusutan berat antara perlakuan 1 dan perlakuan 3 hampir sama sekitar $\pm 26 \%$. Penyusutan ini disebabkan oleh lama pengeringan 10 jam dan dengan suhu $60^{\circ} \mathrm{C}$. Hasil analisa sidik ragam menunjukkan bahwa rendemen manisan kering buah nipah dengan konsentrasi gula yang berbeda yang dihasilkan tidak berbeda nyata. Rendemen manisan kering buah nipah cenderung sama.

Tabel 14. Analisa Sidik Ragam Rendemen Manisan Buah Nipah

\begin{tabular}{ccccccc}
\hline $\begin{array}{c}\text { Sumber } \\
\text { Keragaman }\end{array}$ & $\begin{array}{c}\text { Derajat } \\
\text { Bebas }\end{array}$ & $\begin{array}{c}\text { Jumlah } \\
\text { Kuadrat }\end{array}$ & $\begin{array}{c}\text { Kuadrat } \\
\text { Tengah }\end{array}$ & Fhitung & \multicolumn{2}{c}{ Ftabel } \\
\hline $\begin{array}{c}\text { Perlakuan } \\
\text { Galat }\end{array}$ & 2 & 45,33 & 0,011 & $0,01^{\text {tn }}$ & $5,14^{\text {tn }}$ & 10,92 \\
\hline Total & 6 & 0,22 & 7,56 & & & \\
\hline
\end{tabular}

Keterangan: $\left({ }^{\mathrm{tn}}\right)$ tidak berbeda nyata

Tabel 15. Kadar Gula Manisan Buah Nipah

\begin{tabular}{|c|c|c|c|c|c|}
\hline \multirow{2}{*}{ Perlakuan } & \multicolumn{3}{|c|}{ Ulangan } & \multirow{2}{*}{ Jumlah } & \multirow{2}{*}{ Rata-rata } \\
\hline & 1 & 2 & 3 & & \\
\hline P1 & 11,60 & 12,40 & 12,50 & 36,50 & 12,17 \\
\hline $\mathrm{P} 2$ & 17,90 & 20,50 & 18,90 & 57,30 & 19,10 \\
\hline \multirow[t]{2}{*}{ P3 } & 26,00 & 26,80 & 25,00 & 77,80 & 25,93 \\
\hline & & & & 171,60 & 57,20 \\
\hline
\end{tabular}

Sumber : Data primer setelah diolah (2018),

Keterangan: $\mathrm{P} 1=40 \%$ gula $\mathrm{P} 2=50 \%$ dan $\mathrm{P} 3=60 \%$

\section{H. Kadar Gula (Padatan Terlarut)}

Pengukuran gula (padatan terlarut) menggunakan refractometer dimana perlakuan 1 adalah manisan buah nipah dengan konsentrasi gula 40\%. Perlakuan 2 adalah manisan buah nipah dengan konsentrasi gula 50\%. Perlakuan 3 adalah manisan buah nipah dengan konsentrasi gula $60 \%$.

Hasil pengujian padatan terlarut didapatkan bahwa dari ketiga perlakuan tersebut P3 dengan pembuatan manisan buah nipah dengan konsentrasi gula $60 \%$ memiliki nilai derajat brix tertinggi yaitu $25.93 \%$. P2 dengan pembuatan manisan buah nipah dengan konsentrasi gula $50 \%$ memiliki nilai derajat brix lebih rendah dari perlakuan 3 dan lebih tinggi dari perlakuan 1 yaitu $19.10 \%$. P1 dengan pembuatan manisan buah nipah dengan konsentrasi gula $40 \%$ memiliki nilai derajat brix terendah yaitu $12.17 \%$.

Tabel 16.Analisa Sidik Ragam Kadar Gula Manisan Buah Nipah

\begin{tabular}{|c|c|c|c|c|c|c|}
\hline \multirow{2}{*}{$\begin{array}{c}\text { Sumber } \\
\text { Keragaman }\end{array}$} & \multirow{2}{*}{$\begin{array}{l}\text { Derajat } \\
\text { Bebas }\end{array}$} & \multirow{2}{*}{$\begin{array}{l}\text { Jumlah } \\
\text { Kuadrat }\end{array}$} & \multirow{2}{*}{$\begin{array}{l}\text { Kuadrat } \\
\text { Tengah }\end{array}$} & \multirow{2}{*}{ Fhitung } & \multicolumn{2}{|c|}{ Ftabel } \\
\hline & & & & & $5 \%$ & $1 \%$ \\
\hline Perlakuan & 2 & 1126,51 & 563,25 & $0,50^{\text {tn }}$ & $5,14^{\text {tn }}$ & 10,92 \\
\hline Galat & 6 & 6718,89 & 1119,81 & & & \\
\hline Total & 8 & 7845,40 & & & & \\
\hline
\end{tabular}


Hasil analisa sidik ragam menunjukkan bahwa kadar gula manisan kering buah nipah dengan konsentrasi gula yang berbeda yang dihasilkan tidak berbeda nyata. Kadar gula manisan kering buah nipah cenderung sama.

\section{KESIMPULAN DAN SARAN}

\section{A. KESIMPULAN}

Kesimpulan dari penelitian ini bahwa nilai sensoris rasa manisan kering buah nipah perlakuan 1 memiliki nilai 3.49 (range suka). Sensoris warna, pada perlakuan 2 memiliki nilai 3.62 (range suka). Sensoris aroma, perlakuan 1 dan 2 memiliki nilai 3.31 (range suka). Sedangkan sensoris tekstur, perlakuan 1 memiliki nilai 3.11 (range suka)

Adapun sifat kimia seperti kadar air yang terendah terdapat pada perlakuan 3 yaitu dengan nilai $11.71 \%$., kadar abu yang terendah terdapat pada perlakuan 2 yaitu dengan nilai $0.20 \%$, rendemen yang tertinggi adalah $\pm 64 \%$. Sedangkan kadar gula tertinggi terdapat pada konsentrasi $60 \%$ yaitu $25.93 \%$.

\section{B. Saran}

Saran dalam penelitian lanjutan adalah perlu dilakukan masa simpan dari manisan buah nipah.

\section{DAFTAR PUSTAKA}

Apriyantono A. 1989. Analisi Pangan. IPB Press. Bogor.

Brautlecht CA. 1953. Starch it's sources, production, and uses.

Reinhold. New York.

Butar-butar F. 2011. Pengaruh Penambahan Konsentrasi Gula Terhadap Kualitas Sirup Mangga Arum Manis Lewat Matang. (Tugas Akhir). Politeknik Pertanian Negeri Samarinda. Samarinda.

Departemen Perindustrian, 1983. Laporan Up Grading Tenaga Pembina Industri Kecil Pengolahan dan Pengawetan Buah-Buahan dan Sayuran. Badan Penelitian dan Pengmbangan Industri. Balai Besar Litbang Industri Hasil Pertanian. Bogor.

Dewan Standarlisasi Nasional Indonesia, 1992. SNI-01-2891-1992 Analisis pangan Standarisasi Nasional Indonesia. Jakarta.
Desrosier, N. W. 1988. Teknologi Pengawetan Pangan. Edisi III. Penerjemah Muchji Mulyohardjo. Jakarta: Universitas Indonesia.

Dixit, S. Pandey RC, Das M and Khanna SK.1995. Food quality surveillance on colours in eatables sold in rural market of Uttar Pradesh. J.Food Sci. Technol. $32: 375-376$

Fachruddin, L. 2006. Membuat Aneka Manisan. Kanisius. Yogyakarta.

Harefa W dan Pato U. 2017. Evaluasi Tingkat Kematangan Buah Terhadap mutu Tepung Pisang Kepok Yang Dihasilkan

Kitamura, S., C. Anwar, A. Chaniago, and S. Baba. 1997. Hanbook of mangroves in Indonesia: Bali and Lombok. Ministry of Indonesia and JICA. Jakarta.

Muchtadi, D., 1989. Petunjuk Laboratorium Evaluasi Nilai Gizi Pangan. Departemen $\mathrm{P}$ dan K, PAU IPB. Bogor.

Moehyi, S. 1992. Penyelennnaraan Makanan Institusi dan J 3oga. Jakarta. Bharata.

Purnomo, H. 1995. Aktivitas Air dan Peranannya dalam Pengawetan Pangan. Jakarta: UI-Press.

Renate D, Nurlismita E. 2015. Penambahan Ekstrak Wortel pada Bakso Ikan Gabus Terhadap Kadar B-Karoten dan Sifat Organoleptiknya

Sanjur, D. 1982. Social and Cultural Perspectives in Nutrition. New Jersey: Engelwood cliffs, Prentice Hall Inc.

Soekarto, S.T, $1985 . \quad$ Penilaian Organoleptik Untuk Industri Pangan dan Hasil Pertanian. Bhatara Karya Aksara. Jakarta.

Saptoningsi, dan A.Jatnika. 2012. Membuat Olahan Buah. Agromeddia Pustaka.Jakarta.

Sudarmadji. 2003. Mikrobiologi Pangan, Yogyakarta; PAU Pangan dan Gizi UGM.

Winarno, F. G., 1993. Pangan, Gizi, teknologi dan Konsumen. PT. Gramedia Pustaka Utama. Jakarta.

Winarno, F.G., 1995. Kimia Pangan dan Gizi. PT. Gramedia Pustaka utama. Jakarta. 